\title{
Exploring Polypyrrole as Extraction Phase for Disposable Pipette Extraction Method for Multiclass Organic Micro-Pollutant Determination in River and Tap Water Using Gas Chromatography-Mass Spectrometry
}

\author{
Ricardo D. Huelsmann, ${ }^{\circledR a}$ Francielle C. Turazzi, ${ }^{b}$ Guilherme M. O. Barra ${ }^{b}$ and \\ Eduardo Carasek $^{\oplus *, a}$ \\ ${ }^{a}$ Departamento de Química, Universidade Federal de Santa Catarina, \\ 88040-900 Florianópolis-SC, Brazil \\ ${ }^{b}$ Departamento de Engenharia Mecânica, Universidade Federal de Santa Catarina, \\ 88040-900 Florianópolis-SC, Brazil
}

\begin{abstract}
The use of a polypyrrole (PPy) is described as an efficient extraction phase for disposable pipette extraction (DPX), in a fast and ruggedized analytical method for simultaneous determination of 18 organic micro-pollutants in water using gas chromatography-mass spectrometry (GC-MS). The DPX-blank pipettes were filled with PPy, a material produced through the chemical polymerization of PPy using iron(III) chloride hexahydrate. The optimized conditions were 5 extraction cycles with $600 \mu \mathrm{L}$ of sample, adjusted to $\mathrm{pH} 9$, and desorption with $150 \mu \mathrm{L}$ of ethyl acetate using 7 cycles with the same aliquot. The calibration curves resulted in determination coefficient $\left(\mathrm{R}^{2}\right)$ higher than 0.9963, the limit of detection (LOD) ranged from 0.4 to $1.5 \mu \mathrm{g} \mathrm{L}^{-1}$, and the limit of quantification (LOQ) were from 1.4 to $5.0 \mu \mathrm{g} \mathrm{L}^{-1}$. Excellent results were obtained for repeatability ( 2.3 to $15 \%$, for $5 \mu \mathrm{g} \mathrm{L}^{-1}$ ) and intermediate precision, varying the day of analyses (3.9 to $15.5 \%$ ) and the pipette tip (3.4 to $22.4 \%$ ). The analyte recovery ranged from 75.4 to $115.0 \%$ for river water, and from 74.9 to $116.2 \%$ for tap water, in three different levels of concentration. The DPX-GC-MS method with PPy was successfully applied to determine the 18 analytes in river and tap water from the cities of Joinville and Florianópolis, Santa Catarina, Brazil.
\end{abstract}

Keywords: disposable pipette extraction, DPX, phthalate esters, organophosphorus pesticides, organochlorine pesticides, endocrine disruptor compounds

\section{Introduction}

Concern about the presence of organic micro-pollutants in natural waters is increasing, given the negative impacts on the health of various organisms, including humans. ${ }^{1,2}$ Originating from various sources, these (generally unnatural) compounds have been the subject of international debate. Some classes of these contaminants are agrochemicals (pesticides), ${ }^{3}$ personal care products $(\mathrm{PCP})^{4}$ and plasticizers. ${ }^{5}$

As regards agrochemicals, organophosphorus and organochlorine pesticides (OPPs and OCPs, respectively) are widely used in modern agricultural production. However, OPPs in contact with humans can inhibit acetylcholinesterase, causing nervous system dysfunctions. ${ }^{6,7}$ OCPs, in turn, are much more persistent

*e-mail: eduardo.carasek@ufsc.br in the environment and have deleterious effects on the endocrine system in humans and other organisms. ${ }^{8}$ Personal care products, such as UV filters, despite their positive impact on human health, have been studied due to their negative effects. Some hormonal activity of UV filters has been revealed, added to toxic effects and adverse effects on reproduction in several organisms..$^{910}$ Plasticizers like phthalic acid esters (PAE, also known as phthalates) and alkylphenols (AP) are also endocrine disruptor compounds (EDC), and they are used on a large scale in polymer production and frequently detected in environmental matrices, due the migration and degradation of plastics. ${ }^{11,12}$ In contact with humans, PAE may cause asthma and allergies, besides liver and reproductive toxicity, ${ }^{13}$ while AP can act as estrogens deregulating natural functions. ${ }^{14}$

Parallel to these concerns, there is a growing need for the development of accurate, fast and safe analytical methods for the monitoring of these contaminants in 
aqueous samples. ${ }^{2}$ Analysis of these samples is difficult to perform directly on laboratory analytical instruments, given the following problems: (i) the analyte concentration is very low and the instrument is not able to detect it, and (ii) the matrices generally have characteristics that do not allow compatibility with the instrument (its direct injection can impair the operation of the instrument, or even degrade some components). Thus, sample preparation (which aims to suit the sample to the instrument, preferably pre-concentrating the analytes) is a necessary and very important strategy. ${ }^{2}$

Among the interesting and diversely applicable sample preparation techniques, microextraction techniques have gained a lot of visibility in relation to the classic liquidliquid extraction (LLE) and solid phase extraction (SPE), due to their lower solvent use, easier execution and less tedious work. Solid phase microextraction (SPME), ${ }^{15}$ dispersive liquid-liquid microextraction (DLLME), ${ }^{16}$ hollow fiber liquid-phase microextraction (HF-LPME), ${ }^{17}$ single drop microextraction (SDME) ${ }^{18}$ and disposable pipette extraction (DPX) ${ }^{19}$ are excellent examples of successful techniques that overcome the main problems of classical techniques. The latter draws attention to the extreme ease of application, low cost and low solvent consumption.

Developed and patented by Dr William E. Brewer (University of South Carolina) in $2003,{ }^{20}$ DPX is based on solid phase extraction, with significant reduction in the amount of extractive phase and sample volume, and adaptation of the physical form of the necessary apparatus, also allowing less time of analysis and less volume of organic solvent for desorption compared to SPE. ${ }^{21}$ In this technique, a conventional pipette tip of 1 or $5 \mathrm{~mL}$ capacity is modified with the addition of two filters (one at the bottom and one at the top), and a known amount of extractive phase between these filters. ${ }^{19}$

The process of extraction by DPX is simple and fast, being carried out in a few minutes, using the tip containing the extractive phase, properly connected to the micropipette (or to a syringe). Initially the sorption sites are activated with conditioning done with the use of appropriate solvent, allowing ideal interaction between analyte and the extractive phase. The sample is then aspirated into the tip of the nozzle, mixing with the extractive phase and being dispersed with the subsequent aspiration of air (in this way, the extraction is accelerated and efficient). The sample is then discarded. Finally, the analytes are desorbed with adequate solvent, and there is also air aspiration to favor the process. After elution of the solvent containing the analytes, the extract is sent for analysis in a suitable instrument, and chromatographic methods are the ones most used. ${ }^{21}$
One of the most positive features of DPX is the possibility of using different extractive phases, allowing a wide range of applications that include different matrices and classes of analytes. Some of these materials are biosorbents ${ }^{22,23}$ and synthetic materials, ${ }^{24,25}$ like polypyrrole.

Polypyrrole (PPy), a conductive polymer, is an auspicious and promising alternative as an extraction phase in different sample preparation techniques. ${ }^{26-28}$ The possibility of several interactions between PPy and analytes (including $\pi-\pi$, acid-basic and/or hydrogen bonding) makes PPy an excellent alternative to be a phase extractor in DPX. Adding more qualities, PPy is also highly stable, has high surface area and, especially, is easy to synthesize. ${ }^{25-27,29,30}$

This work aims to develop, optimize and validate a fast and effective method for the determination of 18 organic micro-pollutants of five different classes in environmental waters by DPX using PPy as extraction phase, and gas chromatography-mass spectrometry (GC-MS) for separation and detection.

\section{Experimental}

\section{Reagent and materials}

For the synthesis of the extraction phase, pyrrole (obtained from Sigma-Aldrich, St. Louis USA, distilled under vacuum and stored at $4{ }^{\circ} \mathrm{C}$ before use) and iron(III) chloride hexahydrate (Dinâmica Química, Indaiatuba, Brazil) were used. Acetonitrile (ACN) and methanol $(\mathrm{MeOH})$ were purchased from J.T. Baker (Center Valley, USA) and ethyl acetate (EtOAc) from Sigma-Aldrich (St. Louis, USA). Ultrapure water was daily produced in a purification system (Mega Purity, Billerica, USA).

A stock solution containing a mixture of analytes (20 $\mathrm{mg} \mathrm{L}^{-1}$ each) was prepared in methanol, from individual form of benzophenone, 4-octylphenol (4-OP), terbufos, 4-nonylphenol (4-NP), methyl parathion, metolachlor, chlorpyrifos, aldrin, enzacamene (4-methylbenzylidene camphor), 4,4'-DDE (dichlorodiphenyldichloroethylene), endrin and 4,4'-DDD (dichlorodiphenyldichloroethane) and also from a mixture of EPA Phthalate Esters Mix containing dimethyl phthalate, diethyl phthalate, dibutyl phthalate, benzyl butyl phthalate, bis 2-ethylhexyl phthalate (DEHP) and di- $n$-octyl phthalate (DNOP) (all analytes were obtained from Sigma-Aldrich, St. Louis, USA). A description of all analytes is presented in Table 1.

For ionic strength and $\mathrm{pH}$ adjustments, solutions of sodium chloride (Dinâmica Química, Indaiatuba, Brazil), hydrochloric acid and sodium hydroxide (VETEC, Duque de Caxias, Brazil) were used. Anhydrous sodium sulfate 
Table 1. Analyte abbreviations and information

\begin{tabular}{|c|c|c|c|c|c|}
\hline Analyte & Abbreviation & Class & $\begin{array}{l}\text { Quantification } \\
\text { ion }(\mathrm{m} / \mathrm{z})\end{array}$ & \multicolumn{2}{|c|}{ Identification ion $(\mathrm{m} / \mathrm{z})$} \\
\hline Dimethyl phthalate & DMP & PAE & 163 & 77 & 164 \\
\hline Diethyl phthalate & DEP & PAE & 149 & 177 & 150 \\
\hline Benzophenone & BZP & $\mathrm{PCP}$ & 105 & 77 & 182 \\
\hline 4-Octylphenol & $4-\mathrm{OP}$ & $\mathrm{AP}$ & 107 & 108 & 206 \\
\hline Terbufos & TER & OPP & 231 & 57 & 97 \\
\hline 4-Nonylphenol & 4-NP & $\mathrm{AP}$ & 107 & 220 & 108 \\
\hline Methyl parathion & MPA & OPP & 109 & 263 & 125 \\
\hline Dibutyl phthalate & DBP & PAE & 149 & 150 & 41 \\
\hline Metolachlor & MET & OCP & 162 & 238 & 45 \\
\hline Chlorpyrifos & CHL & OPP & 197 & 97 & 199 \\
\hline Aldrin & ALD & OCP & 66 & 263 & 79 \\
\hline Enzacamene (4-methylbenzylidene camphor) & $4-\mathrm{MBC}$ & PCP & 254 & 128 & 105 \\
\hline 4,4'-DDE (dichlorodiphenyldichloroethylene) & DDE & OCP & 246 & 318 & 248 \\
\hline Endrin & END & $\mathrm{OCP}$ & 81 & 79 & 263 \\
\hline 4,4'-DDD (dichlorodiphenyldichloroethane) & DDD & $\mathrm{OCP}$ & 235 & 237 & 165 \\
\hline Benzyl butyl phthalate & BBP & PAE & 149 & 91 & 206 \\
\hline Bis 2-ethylhexyl phthalate & DEHP & PAE & 149 & 167 & 57 \\
\hline Di- $n$-octyl phthalate & DNOP & PAE & 149 & 279 & 57 \\
\hline
\end{tabular}

PAE: phthalic acid esters; PCP: personal care products; AP: alkylphenols; OPP: organophosphorus pesticides; OCP: organochlorine pesticides.

was obtained from Sigma-Aldrich (St. Louis, USA). The $1 \mathrm{~mL}$ blank pipette tips were purchased from DPX Technologies (Columbia, USA). An analytical standard containing a mixture of polycyclic aromatic hydrocarbons (EPA 525 PAH mix B) used for the robustness test was purchased from Sigma-Aldrich (St. Louis, USA).

\section{Instrumentation}

The chromatographic analyses were performed in a gas chromatography model GC-MS QP 2010 Plus, coupled with a mass spectrometer (Shimadzu, Kyoto, Japan). The separation occurred in a capillary column $(30 \mathrm{~m}$ length, $0.25 \mathrm{~mm}$ of diameter and $0.25 \mu \mathrm{m}$ of stationary phase thickness) model Zebron ${ }^{\mathrm{TM}} \mathrm{Zb}-5 \mathrm{MS}$ (Phenomenex, Torrance, USA). The mobile phase was ultrapure helium (White Martins, Brazil), at constant flow of $1.8 \mathrm{~mL} \mathrm{~min}^{-1}$. The injector, interface and detector temperatures were 300 , 300 and $200^{\circ} \mathrm{C}$, respectively. The initial oven temperature was set to $100{ }^{\circ} \mathrm{C}$, held for $0.5 \mathrm{~min}$, increased to $150{ }^{\circ} \mathrm{C}$ at a rate of $30{ }^{\circ} \mathrm{C} \mathrm{min}{ }^{-1}$, and then increased to $300{ }^{\circ} \mathrm{C}$ at $15{ }^{\circ} \mathrm{C} \mathrm{min}-1$ (held for $1 \mathrm{~min}$ ). Manual injection using splitless mode was used, and the injection volume was $1 \mu \mathrm{L}$. The mass spectrometer operated in electron ionization mode at $70 \mathrm{eV}$. Selected ion monitoring was used, and the selected fragments for quantification and identification of each analyte are presented in Table 1.

\section{Synthesis and characterization of the extraction phase}

For the polypyrrole synthesis, a methodology described by our research group ${ }^{25}$ was followed. In this first work developed by Turazzi et al. ${ }^{25}$ polypyrrole extracting phases were synthesized, two of them containing cetyltrimethylammonium bromide (CTAB) and montmorillonite. The PPy-CTAB phase was successfully applied for determination of polycyclic aromatic hydrocarbons (PAH) and hormones in river water through DPX. For this new alternative, we chose the simplest form, pure PPy.

The chemical in situ polymerization of pyrrole was performed in aqueous solution containing the oxidant iron(III) chloride hexahydrate. Initially, $27.480 \mathrm{~g}$ of $\mathrm{FeCl}_{3} \cdot 6 \mathrm{H}_{2} \mathrm{O}$ were dissolved in $50 \mathrm{~mL}$ of distilled water. Then, $2.964 \mathrm{~g}$ of pyrrole (dispersed in $20 \mathrm{~mL}$ of distilled water) was added to the first mixture, dropwise. The polymerization reaction was carried out for $1 \mathrm{~h}$ under room temperature and magnetic stirring. The conductive polymer was filtered after $24 \mathrm{~h}$ and washed with distilled water. After this process, it was dried at $60{ }^{\circ} \mathrm{C}$, sieved into a 200-mesh sieve and stored in a dry and closed flask until 
the preparation of the tips. The polypyrrole produced was previously characterized by Fourier transform infrared spectroscopy (FTIR), and scanning electron microscopy (SEM) by Turazzi et al..$^{25}$

\section{Preparation of the tips}

DPX blank tips were filled with a known and optimized mass of polypyrrole and sealed with a filter. Each tip containing the extraction material was conditioned using 3 cycles of $300 \mu \mathrm{L}$ of $\mathrm{MeOH}$ before using.

\section{Method optimization}

Steps that make up the DPX method were optimized: initially, the desorption solvent was evaluated, followed by the extraction phase mass and number of extraction cycles. The next optimizations were related to desorption solvent volume and number of desorption cycles using a multivariate approach, and a univariate study on sample $\mathrm{pH}$ and ionic strength was performed.

As a base initial procedure, each experiment was performed with 3 extraction cycles (samples of $600 \mu \mathrm{L}$ of ultrapure water spiked with all the analytes at a constant concentration of $100 \mu \mathrm{g} \mathrm{L}^{-1}$ ), followed by desorption with $300 \mu \mathrm{L}$ of solvent ( 7 cycles with the same aliquot). The final solvent extract was dried with $80 \pm 2 \mathrm{mg}$ of anhydrous $\mathrm{Na}_{2} \mathrm{SO}_{4}$, prior to GC-MS analysis.

\section{Desorption solvent optimization}

The desorption solvents evaluated were $\mathrm{MeOH}, \mathrm{ACN}$ and EtOAc. For this optimization, a simplex-centroid design containing triplicate in central point was applied, also allowing the mixture of solvents to be evaluated.

\section{Extraction phase mass and number of extraction cycles}

A Doehlert design was performed to evaluate the influence of polypyrrole mass contained in the tip, and the number of extraction cycles. In this study, 5, 10 and $15 \mathrm{mg}$ of PPy was inserted into the DPX tips, and the number of cycles were tested from 1 to 5 , using new aliquots of $600 \mu \mathrm{L}$ of sample.

\section{Desorption volume and number of desorption cycles}

For the desorption conditions, a Doehlert design was also performed to visualize the influence of EtOAc (desorption solvent) volume simultaneously with the number of desorption cycles in the analytical response. With nine experiments, the volume of solvent ranged from 150 to $350 \mu \mathrm{L}$, and the number of cycles was tested from 1 to 9 (using the same solvent aliquot).

\section{$\mathrm{pH}$ and ionic strength}

The sample composition was also optimized, in relation to $\mathrm{pH}$ (which may affect the chemical composition distribution of analytes, and also the sorption capacity of the extraction phase) and salt content, in the form of sodium chloride percentage (to study salting-out effect, which could improve the extraction of the analytes). A univariate approach was used in this optimization, through experiments in triplicate, in the $\mathrm{pH}$ range from 3 to 11 , and $\mathrm{NaCl}$ percentages from 0 to $10 \%$.

\section{Robustness}

With the end of the method optimization, the robustness was evaluated, to ensure its quality through small and common experimental errors that may occur during application of the method. These errors could be caused by instrumental imprecision (balance, pHmeter, micropipette) and/or analyst's mistakes (number of cycles to be performed, delayed extraction). The Youden method was applied, where in eight experiments, the effect of seven variables was analyzed. The variables (and their limits) chosen were: PPy mass in the tip (9.5 and $10.5 \mathrm{mg}$, supposing $5 \%$ error in weighing), solution $\mathrm{pH}$ (8.8 and 9.2), sample volume (594 and $606 \mu \mathrm{L})$ and desorption volume (149 and $151 \mu \mathrm{L})$, extraction time ( 0 and $10 \mathrm{~s})$ and number of desorption cycles ( 7 and 8). The seventh variable was set as a possible chemical interferent, the presence/ absence of another organic contaminant in the sample, which may interfere in extraction of the analytes. For this case, the presence of $13 \mathrm{PAH}$ compounds in the summed concentration of $650 \mu \mathrm{g} \mathrm{L}{ }^{-1}$ was evaluated. The final matrix with the combinations of the variables is presented in the Supplementary Information section.

\section{Analytical parameter of merit and method application}

Calibration curves were obtained by plotting the chromatographic peak area versus the concentration, using a blank lake water sample (collected at Lagoa do Peri, Florianópolis, Brazil) checked to be free of all analytes, spiked with seven concentrations of each analyte. Parameters like the determination coefficient $\left(\mathrm{R}^{2}\right)$, limit of detection (LOD, calculated as 3 times the ratio between the standard deviation of the intercept by the slope) and limit of quantification (LOQ, calculated as 10 times the ratio between the standard deviation of the intercept by the slope) were obtained with linear regression of the calibration data, performed with method application. The method's accuracy was verified as relative recoveries of each analyte, in three different concentrations, using river and tap water. The 
method's precision was evaluated in the form of repeatability (also known as intraday precision) measured in three different concentrations in triplicate, and also in the form of intermediate precision, studying the method application with different analysis days (inter-day precision) and different pipette tips (prepared individually by the addition of PPy in the blank DPX tip). The river water sample was collected in the city of Joinville (Rio Comprido), and the tap water sample was collected in a residence in Florianópolis (both cities in Santa Catarina State, Brazil). All the samples were stored in amber and sealed vials at $4{ }^{\circ} \mathrm{C}$ until the moment of analyses.

\section{Results and Discussion}

\section{Extraction phase characterization and preparation of the tips}

The extraction phase synthesis is easy to perform, with no laborious steps. The product is a blue powder, and as previously described by our research group, ${ }^{25}$ its morphology is presented as granular or spherical, containing agglomerates of different sizes, as well as particles with similar sizes, constituting a high porosity surface. These characteristics may enhance the mass transfer of the analytes to the extraction phase during the DPX method application. The synthesized PPy was sieved into a 200 mesh sieve. For the tips preparation, a blank DPX tip was filled with $10 \mathrm{mg}$ of PPy.

\section{Method optimization}

For all the optimization steps, the normalized average peak area of quantification ion (Table 1) of each analyte was used as the analytical response.

\section{Desorption solvent}

The first step to be optimized was the desorption solvent, to ensure that the analytes were efficiently desorbed from the extraction phase. Analyzing the triangular response surface obtained from the simplex-centroid design (Figure 1) obtained with a quadratic function and $\mathrm{R}^{2}$ corresponding to 0.935, it is observed that $\mathrm{MeOH}$ and $\mathrm{ACN}$, the most polar solvents evaluated, have no satisfactory desorption capacities (even in mixtures) with the wide range of analytes.

However, EtOAc showed excellent results when applied in the pure form, indicating better interaction with the analytes (most of which have properties of low polarity), and was chosen as the optimum desorption solvent.

\section{Extraction phase mass and number of extraction cycles}

For the simultaneous optimization of the PPy mass in the tip and the number of extraction cycles applied in

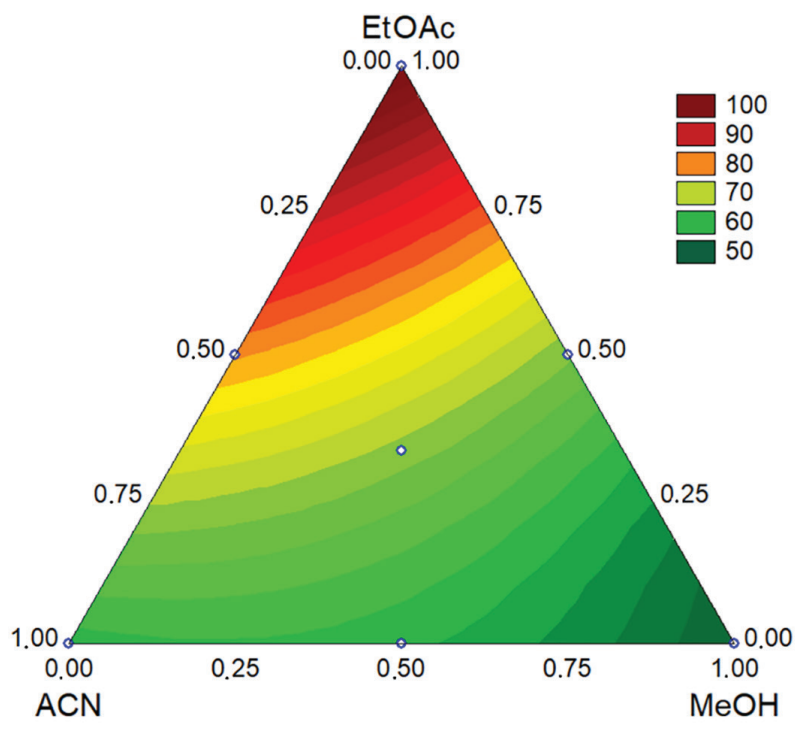

Figure 1. Fitted response surface using a simplex-centroid design, quadratic model $\left(\mathrm{R}^{2}=0.935\right)$, for the optimization of desorption solvent. DPX conditions: $10 \mathrm{mg}$ of PPy, $600 \mu \mathrm{L}$ of ultrapure water spiked with $100 \mu \mathrm{g} \mathrm{L}^{-1}$ of the analytes, 3 extraction cycles, and 7 desorption cycles with $300 \mu \mathrm{L}$ with the same aliquot.

the extraction, a Doehlert design was performed in nine experiments including triplicate in the central point. As can be seen in Figure 2, the maximum response is obtained with the highest number of extraction cycles (indicating a sorptive quality of PPy in the extraction of analytes), and the extraction phase mass has an optimum condition between 10 and $15 \mathrm{mg}$.

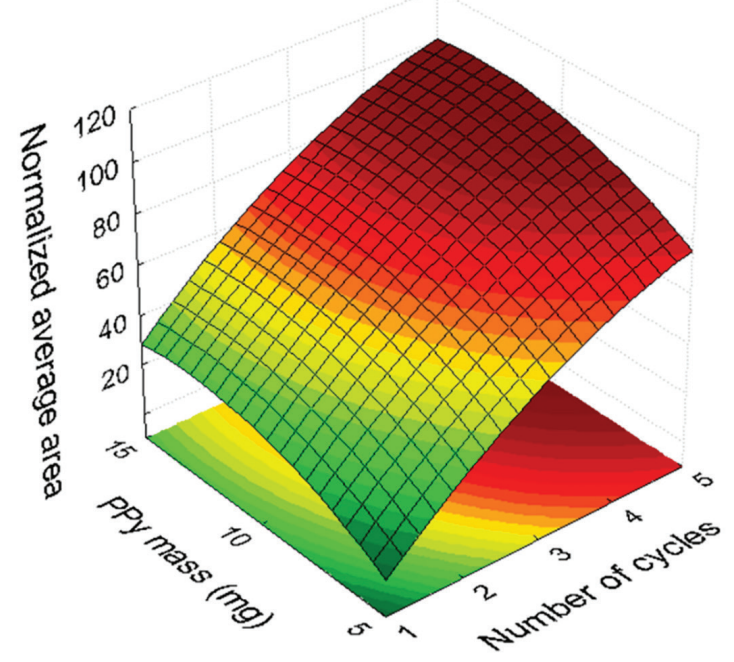

Figure 2. Fitted response surface using a Doehlert design, quadratic model $\left(\mathrm{R}^{2}=0.985\right)$, for the optimization of extraction step. DPX conditions: variable mass of PPy, $600 \mu \mathrm{L}$ of ultrapure water spiked with $100 \mu \mathrm{g} \mathrm{L}^{-1}$ of the analytes, variable extraction cycles, and 7 desorption cycles with $300 \mu \mathrm{L}$ of EtOAc with the same aliquot.

The use of a wide number of extraction cycles allows better sensitivity, given the better enrichment factor caused 
by the extraction of a larger amount of sample. The use of more extraction phase (in this case, larger PPy mass) could also result in better responses, but in this case, masses larger than $10 \mathrm{mg}$ cause problems in the sample dispersion, such as tip clogging. Prioritizing the economy and workability of the material, the optimal condition chosen in this optimization step is $10 \mathrm{mg}$ of PPy and 5 extraction cycles.

\section{Desorption volume and number of desorption cycles}

Related to the desorption step, it was observed that the desorption volume, as well as the number of desorption cycles, affects the analytical response. The desorption efficiency increases with a higher number of desorption cycles, reaching an equilibrium condition close to seven cycles. The relation of the volume to the increase of the analytical response is inverse, since smaller volumes for desorption give more preconcentration, as the analytes get dissolved in a smaller amount of solvent for the injection in the GC-MS. This can be seen in Figure 3, where the normalized average area increases from 350 to $150 \mu \mathrm{L}$.

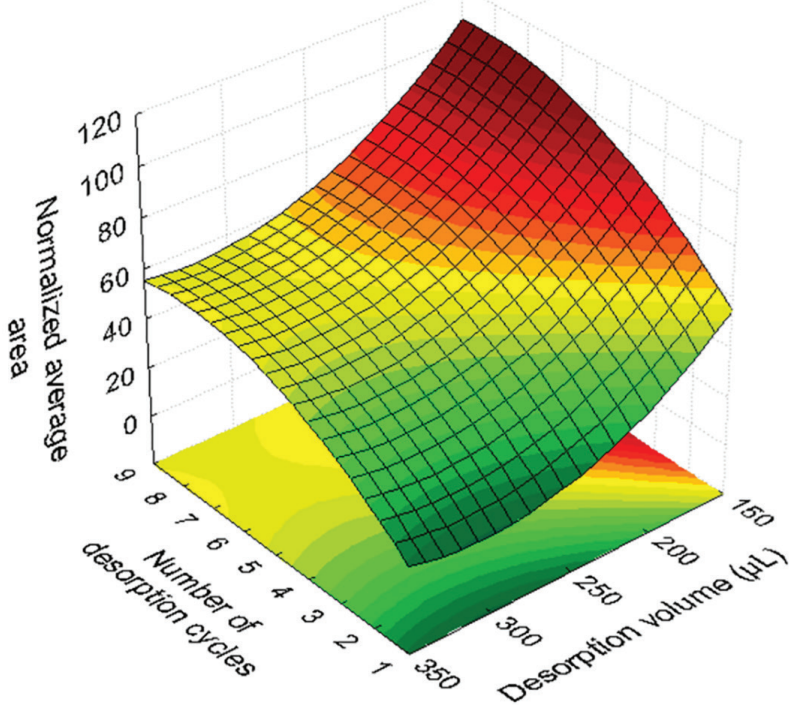

Figure 3. Fitted response surface using a Doehlert design, quadratic model $\left(\mathrm{R}^{2}=0.919\right)$, for the optimization of desorption step. DPX conditions: $10 \mathrm{mg}$ of PPy, $600 \mu \mathrm{L}$ of ultrapure water spiked with $100 \mu \mathrm{g} \mathrm{L}{ }^{-1}$ of the analytes, 5 extraction cycles, and variable desorption cycles with variable volumes of EtOAc with the same aliquot.

Although it may seem that the best condition still requires lower volumes, these conditions were not evaluated because of an experimental limitation: volumes lower than $150 \mu \mathrm{L}$ do not allow a dispersive desorption, since it is not capable of encompassing all extraction phase masses. Considering this characteristic, the optimum condition obtained with this optimization is 7 desorption cycles using $150 \mu \mathrm{L}$ of EtOAc.

\section{$\mathrm{pH}$ and ionic strength}

The values of $\mathrm{pH}$ and ionic strength (studied as percentage of $\mathrm{NaCl}$ ) are important chemical characteristics of the sample, because they may influence the distribution of the analytes between the extraction phase and the solution. By optimizing these factors, it is possible to improve the sensitivity and precision of the analytical method. The sample $\mathrm{pH}$ was evaluated from 3 to 11 , and the results show that the best condition for the extraction of the analytes is $\mathrm{pH} 9$ (Figure 4).

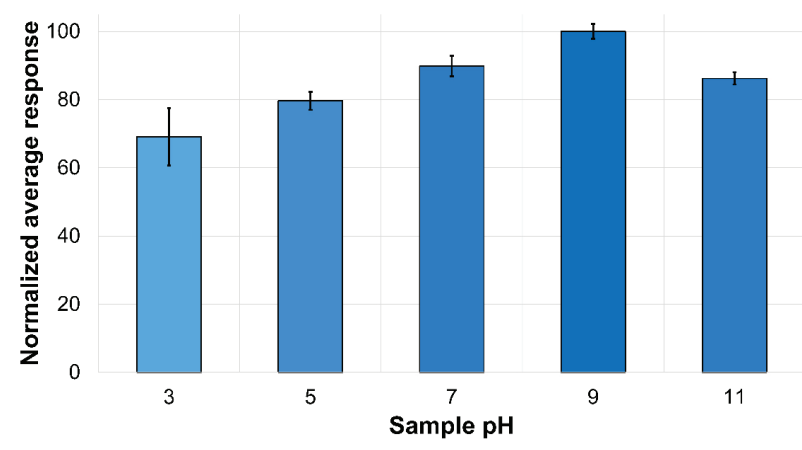

Figure 4. Bar graph for the sample $\mathrm{pH}$ optimization. DPX conditions: $10 \mathrm{mg}$ of PPy, $600 \mu \mathrm{L}$ of ultrapure water spiked with $100 \mu \mathrm{g} \mathrm{L}{ }^{-1}$ of the analytes, 5 extraction cycles, and 7 desorption cycles with $150 \mu \mathrm{L}$ of EtOAc with the same aliquot.

The extremely high $\mathrm{pH}$ (11) may not be interesting because some analytes have $\mathrm{p} K_{\mathrm{a}}$ closer to 10 (4-OP and 4-NP), so these majority forms may be dissociated and not extracted by PPy. Lower values of $\mathrm{pH}$ (3 and 5) were also not good, possibly due to protonation of the extraction phase. Pei and Qian ${ }^{31}$ described in 1991 the protonation of PPy in the pH region of 2 to 4, which corroborates the explanation of the drop in sensitivity at low $\mathrm{pH}$ values.

The sodium chloride percentage evaluated from 0 to $10 \%$ showed that the presence of this salt decreased the extraction of the analytes (Figure 5). It was also experimentally visualized, especially with higher concentrations of salt: the sample in these conditions is more viscous, and the main characteristic of the DPX extraction method, which is the possibility of a dispersive mixture during extraction, is severely affected and the extraction efficiency is reduced.

Therefore, the optimum DPX condition was set as: 5 extraction cycles with $600 \mu \mathrm{L}$ of sample (pH 9, no salt added), followed by 7 desorption cycles with same aliquot of $150 \mu \mathrm{L}$ of ethyl acetate. The final extract is dried with $80 \mathrm{mg}$ of $\mathrm{Na}_{2} \mathrm{SO}_{4}$ prior to GC-MS analyses.

\section{Robustness}

As can be seen in Figure 6 (Lenth plot), the method proved to be robust against the variations in the factors chosen in the 


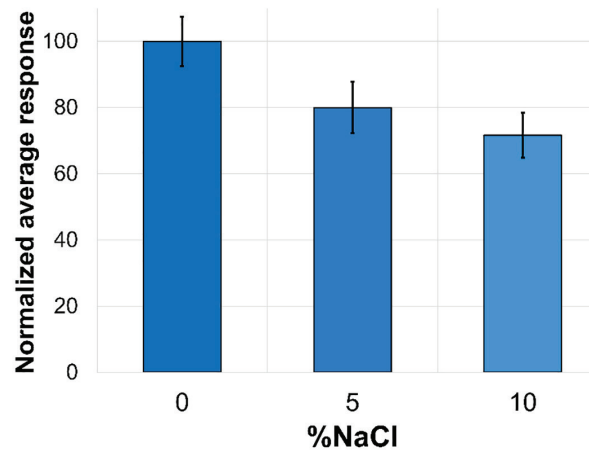

Figure 5. Bar graph for the sample salt content optimization. DPX conditions: $10 \mathrm{mg}$ of PPy, $600 \mu \mathrm{L}$ of ultrapure water spiked with $100 \mu \mathrm{g} \mathrm{L}-1$ of the analytes, $\mathrm{pH}$ adjusted to 9,5 extraction cycles, and 7 desorption cycles with $150 \mu \mathrm{L}$ of EtOAc with the same aliquot.

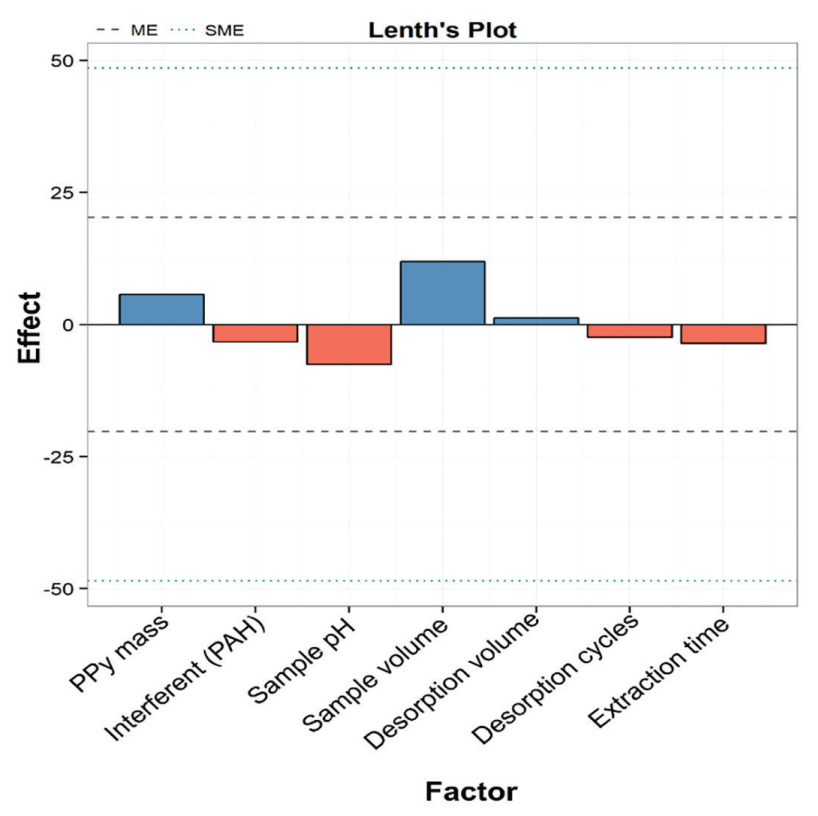

Figure 6. Lenth plot for the DPX-GC-MS method's robustness evaluation.

experiments. None of the factors had effects greater than the margin of error (ME), and consequently were also smaller than the simultaneous margin of error (SME). As expected, factors like the amount of extraction phase and the sample volume had positive effects, indicating that experiments performed under maximal conditions of these factors result in larger responses (but this increase in response is not quantitatively significant). All the other factors (instrumental and experimental) had little effect on the response, indicating the quality of the proposed method, which was also robust against the presence of interferents in high concentrations (PAH in total concentration of $650 \mu \mathrm{g} \mathrm{L} \mathrm{L}^{-1}$ ).

\section{Analytical parameters of merit and method application}

The analytical parameters of merit obtained through optimized conditions are described in Table 2. The determination coefficients were all higher than 0.9963 , indicating good linear relationships with all analytes. Excellent limits of detection were achieved, ranging from $0.4 \mu \mathrm{g} \mathrm{L}^{-1}$ for dimethyl phthalate to $1.5 \mu \mathrm{g} \mathrm{L}^{-1}$ for several analytes. In the same way, the LOQ ranged from 1.4 to $5 \mu \mathrm{g} \mathrm{L}{ }^{-1}$, and the linear range reached $100 \mu \mathrm{g} \mathrm{L}^{-1}$.

The method also showed excellent precision, which was evaluated in three different ways: $(i)$ the repeatability (intraday precision) ranged from 2.3 to $15 \%$ for the lowest concentration $\left(5 \mu \mathrm{g} \mathrm{L}^{-1}\right)$ and from 1.5 to $10.3 \%$ for the highest concentration $\left(100 \mu \mathrm{g} \mathrm{L}^{-1}\right)$; (ii) the inter-day precision also was satisfactory, ranging from 3.6 to $15.5 \%$, as was the intermediate precision (iii) related to the use of different prepared tips for the extraction (ranging from 3.4 to $22.4 \%$ ).

The relative recoveries in two different samples, evaluated in three different concentration levels, indicated the method's good accuracy (Table 3). These recovery values ranged from 75.4 to $115.0 \%$ for river water, and from 74.9 to $116.1 \%$ for tap water, and are in accordance with international guidelines. ${ }^{32}$

The method was applied to determine the 18 analytes in environmental waters from the cities of Joinville and Florianópolis (Santa Catarina, Brazil), and none of the analytes were detected. Exemplary chromatograms are shown in Figure S1 (Supplementary Information), addressing the selectivity and accuracy of the method.

A comparison with other previously published methods is presented in Table 4. It can be observed that methods are usually developed for one or two classes of contaminants: the method proposed here, however, applies to five different classes.

The required sample volume is generally larger than $10 \mathrm{~mL}$ and may be larger than $100 \mathrm{~mL}$ in some cases. The DPX-GC-MS method requires only $3 \mathrm{~mL}$, facilitating sample collection and transport. In addition, the method developed in this paper has shorter extraction times than others, with similar limits of detection.

Although some analytes are contaminants of emerging concern (do not have environmental legislation in force for their determination in water samples), the method developed fits, for example, within the nationally required limits for the determination of metolachlor (MET) in fresh waters, according to CONAMA (National Council for the Environment) Resolution 357, ${ }^{41}$ which defines the concentration of $10 \mu \mathrm{g} \mathrm{L}^{-1}$ as the maximum value (the LOD the method for MET is $1.4 \mu \mathrm{g} \mathrm{L}-1$ ). According to CONAMA Resolution $396,{ }^{42}$ which provides for the classification and environmental guidelines for groundwater classification, the method is compatible for determining chlorpyrifos (maximum allowed value of $30 \mu \mathrm{g} \mathrm{L}^{-1}$, and LOD of the 
Table 2. Analytical parameters of merit (limits of detection and quantification, correlation coefficients, linear range and precision) for the proposed method

\begin{tabular}{|c|c|c|c|c|c|c|c|c|c|}
\hline \multirow[t]{2}{*}{ Analyte } & \multirow{2}{*}{$\begin{array}{l}\mathrm{LOD} / \\
\left(\mu \mathrm{g} \mathrm{L}^{-1}\right)\end{array}$} & \multirow{2}{*}{$\begin{array}{l}\text { LOQ / } \\
\left(\mu \mathrm{g} \mathrm{L}^{-1}\right)\end{array}$} & \multirow[t]{2}{*}{$\mathrm{R}^{2}$} & \multirow{2}{*}{$\begin{array}{l}\text { Linear range / } \\
\left(\mu \mathrm{g} \mathrm{L}^{-1}\right)\end{array}$} & \multicolumn{3}{|c|}{ Repeatability / \% } & \multicolumn{2}{|c|}{$\begin{array}{l}\text { Intermediate precision } \\
\qquad\left(100 \mu \mathrm{g} \mathrm{L}^{-1}\right) / \%\end{array}$} \\
\hline & & & & & $5 \mu \mathrm{g} \mathrm{L}^{-1}$ & $10 \mu \mathrm{g} \mathrm{L}^{-1}$ & $100 \mu \mathrm{g} \mathrm{L}^{-1}$ & Inter-day & Inter-tips \\
\hline DMP & 0.4 & 1.4 & 0.9998 & $1.4-100$ & 12.9 & 8.1 & 5.6 & 13.7 & 13.6 \\
\hline DEP & 0.7 & 2.3 & 0.9994 & $2.3-100$ & 2.3 & 2.5 & 4.4 & 15.5 & 14.9 \\
\hline BZP & 1.2 & 4.0 & 0.9983 & $4.0-100$ & 8.1 & 3.0 & 4.1 & 7.9 & 3.4 \\
\hline 4-OP & 1.4 & 4.5 & 0.9979 & $4.5-100$ & 15.0 & 5.2 & 2.8 & 14.2 & 14.1 \\
\hline TER & 1.5 & 5.0 & 0.9974 & $5.0-100$ & 6.8 & 8.7 & 1.5 & 12.9 & 17.3 \\
\hline 4-NP & 1.5 & 5.0 & 0.9968 & $5.0-100$ & 4.7 & 11.1 & 3.6 & 13.0 & 14.0 \\
\hline MPA & 1.1 & 3.5 & 0.9987 & $3.5-100$ & 13.6 & 21.3 & 10.3 & 14.9 & 22.4 \\
\hline DBP & 1.5 & 5.0 & 0.9972 & $5.0-100$ & 7.2 & 2.5 & 2.5 & 3.6 & 3.7 \\
\hline MET & 1.4 & 4.6 & 0.9978 & $4.6-100$ & 3.8 & 4.9 & 9.2 & 13.5 & 9.2 \\
\hline CHL & 1.5 & 4.9 & 0.9975 & $4.9-100$ & 3.5 & 4.5 & 5.6 & 13.0 & 11.0 \\
\hline ALD & 1.5 & 5.0 & 0.9972 & $5.0-100$ & 9.4 & 9.2 & 4.7 & 13.6 & 5.6 \\
\hline 4-MBC & 1.4 & 4.7 & 0.9977 & $4.7-100$ & 5.1 & 7.9 & 2.0 & 8.3 & 6.9 \\
\hline DDE & 1.4 & 4.7 & 0.9977 & $4.7-100$ & 4.2 & 2.2 & 2.8 & 8.8 & 7.0 \\
\hline END & 1.5 & 5.0 & 0.9963 & $5.0-100$ & 7.2 & 8.1 & 3.9 & 4.3 & 11.5 \\
\hline DDD & 1.5 & 5.0 & 0.9965 & $5.0-100$ & 8.6 & 11.2 & 2.0 & 7.2 & 11.1 \\
\hline BBP & 0.7 & 2.2 & 0.9995 & $2.2-100$ & 2.5 & 2.8 & 3.1 & 11.8 & 14.2 \\
\hline DEHP & 1.1 & 3.5 & 0.9986 & $3.5-100$ & 12.3 & 5.9 & 1.9 & 12.4 & 18.8 \\
\hline DNOP & 1.0 & 3.2 & 0.9988 & $3.2-100$ & 4.7 & 6.0 & 2.8 & 12.3 & 10.2 \\
\hline
\end{tabular}

LOD: limit of detection; LOQ: limit of quantification; $\mathrm{R}^{2}$ : determination coefficient; DMP: dimethyl phthalate; DEP: diethyl phthalate; BZP: benzophenone; 4-OP: 4-octylphenol; TER: terbufos; 4-NP: 4-nonylphenol; MPA: methyl parathion; DBP: dibutyl phthalate; MET: metolachlor; CHL: chlorpyrifos; ALD: aldrin; 4-MBC: enzacamene (4-methylbenzylidene camphor); DDE: 4,4'-DDE (dichlorodiphenyldichloroethylene); END: endrin; DDD: 4,4'-DDD (dichlorodiphenyldichloroethane); BBP: benzyl butyl phthalate; DEHP: bis 2-ethylhexyl phthalate; DNOP: di-n-octyl phthalate.

Table 3. Results of recoveries in the two different water samples

\begin{tabular}{|c|c|c|c|c|c|c|}
\hline \multirow{3}{*}{ Analyte } & \multicolumn{6}{|c|}{ Relative recovery / \% } \\
\hline & \multicolumn{3}{|c|}{ River water } & \multicolumn{3}{|c|}{ Tap water } \\
\hline & $5.0 \mu \mathrm{g} \mathrm{L}^{-1}$ & $10.0 \mu \mathrm{g} \mathrm{L}^{-1}$ & $50.0 \mu \mathrm{g} \mathrm{L}^{-1}$ & $5.0 \mu \mathrm{g} \mathrm{L}^{-1}$ & $10.0 \mu \mathrm{g} \mathrm{L}^{-1}$ & $50.0 \mu \mathrm{g} \mathrm{L}^{-1}$ \\
\hline DMP & 108.8 & 98.6 & 98.8 & 96.3 & 108.9 & 101.4 \\
\hline DEP & 112.8 & 101.4 & 84.2 & 101.5 & 100.0 & 106.6 \\
\hline BZP & 91.2 & 87.7 & 75.4 & 101.9 & 77.7 & 84.6 \\
\hline $4-\mathrm{OP}$ & 102.2 & 90.7 & 82.7 & 87.0 & 105.7 & 98.3 \\
\hline TER & 95.6 & 85.5 & 84.0 & 101.2 & 101.1 & 89.4 \\
\hline 4-NP & 78.1 & 77.1 & 85.4 & 85.1 & 94.6 & 86.6 \\
\hline MPA & 96.4 & 91.5 & 89.3 & 97.8 & 88.2 & 87.7 \\
\hline DBP & 100.9 & 95.2 & 86.3 & 113.3 & 111.3 & 94.5 \\
\hline MET & 86.3 & 91.4 & 87.2 & 95.1 & 105.6 & 91.3 \\
\hline CHL & 81.0 & 90.6 & 84.8 & 116.1 & 106.3 & 88.2 \\
\hline ALD & 92.4 & 106.3 & 104.1 & 115.1 & 108.3 & 101.4 \\
\hline 4-MBC & 92.9 & 94.9 & 92.4 & 113.7 & 111.7 & 91.9 \\
\hline DDE & 107.5 & 115.0 & 95.7 & 114.8 & 97.8 & 79.7 \\
\hline END & 84.8 & 82.4 & 81.4 & 112.7 & 108.7 & 87.8 \\
\hline DDD & 80.6 & 76.6 & 82.7 & 90.9 & 90.8 & 74.9 \\
\hline BBP & 79.1 & 82.2 & 77.4 & 108.2 & 111.1 & 81.0 \\
\hline DEHP & 103.5 & 99.8 & 110.7 & 108.9 & 105.3 & 84.1 \\
\hline DNOP & 84.0 & 79.9 & 111.7 & 107.9 & 102.1 & 88.5 \\
\hline
\end{tabular}

DMP: dimethyl phthalate; DEP: diethyl phthalate; BZP: benzophenone; 4-OP: 4-octylphenol; TER: terbufos; 4-NP: 4-nonylphenol; MPA: methyl parathion; DBP: dibutyl phthalate; MET: metolachlor; CHL: chlorpyrifos; ALD: aldrin; 4-MBC: enzacamene (4-methylbenzylidene camphor); DDE: 4,4'-DDE (dichlorodiphenyldichloroethylene); END: endrin; DDD: 4,4'-DDD (dichlorodiphenyldichloroethane); BBP: benzyl butyl phthalate; DEHP: bis 2-ethylhexyl phthalate; DNOP: di- $n$-octyl phthalate. 
Table 4. Comparison between the developed method and recently reported methods in literature

\begin{tabular}{|c|c|c|c|c|c|c|c|}
\hline Analyte class & Sample & $\begin{array}{l}\text { Extraction } \\
\text { technique }\end{array}$ & Instrumentation & $\begin{array}{c}\text { Sample } \\
\text { volume / } \mathrm{mL}\end{array}$ & $\begin{array}{l}\text { Extraction } \\
\text { time / min }\end{array}$ & $\begin{array}{l}\mathrm{LOD} / \\
\left(\mu \mathrm{g} \mathrm{L}^{-1}\right)\end{array}$ & Reference \\
\hline PAE & $\begin{array}{l}\text { river, tap and bottled } \\
\text { mineral water }\end{array}$ & MSPE & HPLC-DAD & 20 & 16 & $0.08-0.24$ & 33 \\
\hline PAE & tap water & SPE & GC-MS & 10 & 35 & $0.1-10$ & 34 \\
\hline OPP & river water and juices & ET-DLLME & GC-FID & 50 & $>9$ & $0.82-1.65$ & 35 \\
\hline $\mathrm{OPP}$ and $\mathrm{OCP}$ & surface estuarine water & SPE & GC-MS & 500 & $>160$ & $0.007-0.061$ & 36 \\
\hline РCP & swimming pool water & SPMD & HPLC-DAD & passive sampling & $24 \mathrm{~h}$ & $0.2-0.9$ & 37 \\
\hline AP & surface water & $\mathrm{BA} \mu \mathrm{E}-\mathrm{LD}$ & HPLC-DAD & 25 & $>16 \mathrm{~h}$ & 0.3 & 38 \\
\hline $\mathrm{OCP}$ and $\mathrm{AP}$ & wastewater & DLLME & GC-MS & 8 & 2 & $0.17-1.5$ & 39 \\
\hline OCP & seawater & SPE & GC-ECD & 100 & - & $0.28-0.51$ & 40 \\
\hline $\begin{array}{l}\text { PAE, OPP, OCP, } \\
\text { PCP and AP }\end{array}$ & river and tap water & DPX & GC-MS & 3 & $<3$ & $0.4-1.5$ & this work \\
\hline
\end{tabular}

LOD: limit of detection; PAE: phthalic acid esters; MSPE: magnetic solid phase extraction; HPLC-DAD: high performance liquid chromatographydiode array detector; GC-MS: gas chromatography-mass spectrometry; OPP: organophosphorus pesticides; ET-DLLME: elevated temperature dispersive liquid-liquid microextraction; GC-FID: gas chromatography-flame ionization detector; OCP: organochlorine pesticides; PCP: personal care products; SPMD: semi-permeable membrane device; AP: alkylphenols; BA $\mu$ E-LD: bar adsorptive microextraction-liquid desorption; GC-ECD: gas chromatographyelectron capture detector; DPX: disposable pipette extraction.

$1.5 \mu \mathrm{g} \mathrm{L}^{-1}$ ), DDE and DDD (maximum allowed value of $2 \mu \mathrm{g} \mathrm{L}{ }^{-1}$, and LOD of the method of 1.4 and $1.5 \mu \mathrm{g} \mathrm{L} \mathrm{L}^{-1}$, respectively) in drinking water.

According to international legislation, DEHP determination is also possible using the proposed method, in bottled water according to U.S. Department of Health \& Human Services (FDA 21CFR 165$)^{43}$ whose maximum limit is $6 \mu \mathrm{g} \mathrm{L}^{-1}$, and also in surface waters with Directive 2008/105/EC of the European Parliament and of the Council, ${ }^{44}$ whose maximum limit is $1.3 \mu \mathrm{g} \mathrm{L}{ }^{-1}$ (the method is capable of detecting $1.1 \mu \mathrm{g} \mathrm{L}^{-1}$ ). This same legislation indicates that the maximum of 4-NP is $2.0 \mu \mathrm{g} \mathrm{L}^{-1}$ (LOD employing the method is $1.5 \mu \mathrm{g} \mathrm{\textrm {L } ^ { - 1 }}$ ). This information indicates the good applicability of the proposed method.

\section{Conclusions}

In this study, an efficient methodology for simultaneous extraction and determination of 18 organic micro-pollutants from five different classes was successfully developed. Using a new extraction phase for the DPX technique, this method is effective, fast, precise and robust. The PPy synthesis is easy to perform, and was followed by characterization using FTIR and SEM. Through univariate and multivariate optimizations, the method reached excellent results in the sense of LOD and linear range, as well as for recoveries and precision.

Comparing the method with others developed in the literature, one can see a significant improvement in the field of sample preparation, using a low volume of sample, low solvent consumption, and high throughput with extraction time lower than $3 \mathrm{~min}$.

\section{Supplementary Information}

Additional material related to this work can be found in the online version, as supplementary information, free of charge at http://jbcs.sbq.org.br as PDF file.

\section{Acknowledgments}

This study was financed in part by the Coordenação de Aperfeiçoamento de Pessoal de Nível Superior, Brazil (CAPES), finance code 001. The authors are also grateful to the Conselho Nacional de Desenvolvimento Científico e Tecnológico $(\mathrm{CNPq})$ for financial support.

\section{References}

1. Lapworth, D. J.; Baran, N.; Stuart, M. E.; Ward, R. S.; Environ. Pollut. 2012, 163, 287.

2. Carasek, E.; Merib, J.; Mafra, G.; Spudeit, D.; TrAC, Trends Anal. Chem. 2018, 108, 203.

3. Carvalho, F. P.; Food Energy Secur. 2017, 6, 48.

4. Petrie,B.;Barden, R.; Kasprzyk-Hordern,B.; WaterRes. 2015, 72,3.

5. Luo, Q.; Liu, Z.; Yin, H.; Dang, Z.; Wu, P.; Zhu, N.; Lin, Z.; Liu, Y.; Water Res. 2018, 147, 362.

6. Ismail, A. A.; Wang, K.; Olson, J. R.; Bonner, M. R.; Hendy, O.; Rasoul, G. A.; Rohlman, D. S.; J. Toxicol. Environ. Health, Part A 2017, 80, 542.

7. Kang, J.; Zettel, V. H.; Ward, N. I.; J. Nutr. Environ. Med. 1995, $5,325$.

8. Pleština, R. In Encyclopedia of Food Sciences and Nutrition; Caballero, B.; Trugo, L.; Finglas, P. M., eds.; Elsevier: Amsterdam, 2003, p. 4473-4483. 
9. Zhang, Q.; Ma, X.; Dzakpasu, M.; Wang, X. C.; Ecotoxicol. Environ. Saf. 2017, 142, 338.

10. Fent, K.; Zenker, A.; Rapp, M.; Environ. Pollut. 2010, 158, 1817.

11. Reichert, G.; Hilgert, S.; Fuchs, S.; Azevedo, J. C. R.; Environ. Pollut. 2019, 255, 113140.

12. He, M.-J.; Lu, J.-F.; Wang, J.; Wei, S.-Q.; Hageman, K. J.; Sci. Total Environ. 2020, 698, 134264.

13. Sathyanarayana, S.; Curr. Probl. Pediatr. Adolesc. Health Care 2008, 38, 34.

14. Crisp, T. M.; Clegg, E. D.; Cooper, R. L.; Wood, W. P.; Anderson, D. G.; Baetcke, K. P.; Hoffmann, J. L.; Morrow, M. S.; Rodier, D. J.; Schaeffer, J. E.; Touart, L. W.; Zeeman, M. G.; Patel, Y. M.; Environ. Health Perspect. 1998, 106, 11.

15. do Carmo, S. N.; Merib, J.; Dias, A. N.; Stolberg, J.; Budziak, D.; Carasek, E.; J. Chromatogr. A 2017, 1525, 23.

16. Ahmad, W.; Al-Sibaai, A. A.; Bashammakh, A. S.; Alwael, H.; El-Shahawi, M. S.; TrAC, Trends Anal. Chem. 2015, 72, 181.

17. Fernandez, M. A. M.; André, L. C.; Cardeal, Z. L.; J. Chromatogr. A 2017, 1481, 31.

18. Kokosa, J. M.; TrAC, Trends Anal. Chem. 2015, 71, 194.

19. Pinto, M. A. L.; Queiroz, M. E. C.; Sci. Chromatogr. 2015, 7, 101.

20. Brewer, W.; US pat. $6566145 B 22003$.

21. Bordin, D. C. M.; Alves, M. N. R.; de Campos, E. G.; de Martinis, B. S.; J. Sep. Sci. 2016, 39, 1168.

22. Mafra, G.; Spudeit, D.; Brognoli, R.; Merib, J.; Carasek, E.; J. Chromatogr. B 2018, 1102-1103, 159.

23. Morés, L.; da Silva, A. C.; Merib, J.; Dias, A. N.; Carasek, E.; J. Sep. Sci. 2019, 42, 1404.

24. Corazza, G.; Merib, J.; Magosso, H. A.; Bittencourt, O. R.; Carasek, E.; J. Chromatogr. A 2017, 1513, 42.

25. Turazzi, F. C.; Morés, L.; Carasek, E.; Merib, J.; Barra, G. M. O.; J. Environ. Chem. Eng. 2019, 7, 103156.

26. Atoi, P. A.; Talebpour, Z.; Fotouhi, L.; J. Chromatogr. A 2019, $1604,460478$.
27. Dogaheh, M. A.; Behzadi, M.; J. Pharm. Anal. 2019, 9, 185.

28. Wei, L.; Yan, Y.; Deng, J.; Ma, Y.; Wang, Y.; Wu, X.; Kang, X.; J. Braz. Chem. Soc. 2018, 29, 2137.

29. Xie, L.; Huang, J.; Han, Q.; Song, Y.; Liu, P.; Kang, X.; J. Chromatogr. A 2019, 1589, 30.

30. Bagheri, H.; Ayazi, Z.; Naderi, M.; Anal. Chim. Acta 2013, 767, 1.

31. Pei, Q.; Qian, R.; Synth. Met. 1991, 45, 35.

32. Rambla-Alegre, M.; Esteve-Romero, J.; Carda-Broch, S.; J. Chromatogr. A 2012, 1232, 101.

33. Liu, X.; Sun, Z.; Chen, G.; Zhang, W.; Cai, Y.; Kong, R.; Wang, X.; Suo, Y.; You, J.; J. Chromatogr. A 2015, 1409, 46.

34. Huang, D.; Wang, X.; Deng, C.; Song, G.; Cheng, H.; Zhang, X.; J. Chromatogr. A 2014, 1325, 65.

35. Farajzadeh, M. A.; Mogaddam, M. R. A.; Aghdam, S. R.; Nouri, N.; Bamorrowat, M.; Food Chem. 2016, 212, 198.

36. Rocha, M. J.; Ribeiro, M. F. T.; Cruzeiro, C.; Figueiredo, F.; Rocha, E.; Int. J. Environ. Anal. Chem. 2012, 92, 1587.

37. Lima, M. F.; Pacheco, W. F.; Cassella, R. J.; J. Chromatogr. A 2019, 1600, 23.

38. Neng, N.; Nogueira, J.; Molecules 2014, 19, 9369.

39. Chormey, D. S.; Firat, M.; Bakırdere, S.; Water, Air, Soil Pollut. 2018, 229, 370.

40. Mehdinia, A.; J. Braz. Chem. Soc. 2014, 25, 2048.

41. http://www2.mma.gov.br/port/conama/legiabre. cfm?codlegi $=459$, accessed in June 2020.

42. http://www2.mma.gov.br/port/conama/legiabre. cfm?codlegi $=562$, accessed in June 2020.

43. https://gov.ecfr.io/cgi-bin/text-idx ?SID=f1863a027cfa3393d 0ca16783084b1bd\&mc $=$ true $\&$ node $=$ pt21.2.165\&rgn $=\operatorname{div} 5$, accessed in June 2020.

44. https://eur-lex.europa.eu/eli/dir/2008/105/oj, accessed in June 2020.

Submitted: March 27, 2020

Published online: June 18, 2020 